\title{
Influence of bound hydrogen states on BO-regeneration kinetics and consequences for high-speed regeneration processes
}

\author{
Svenja Wilking*, Cornelius Beckh, Sebastian Ebert, Axel Herguth, Giso Hahn \\ University of Konstanz, Department of Physics, P.O. Box 676, 78457 Konstanz, Germany
}

\section{A R T I C L E I N F O}

Keywords:

Silicon

Boron-oxygen

Hydrogen

Regeneration

\begin{abstract}
A B S T R A C T
Recombination active boron oxygen related defects typically limit the efficiency of solar cells made from boron doped, oxygen rich silicon. This limitation can be overcome by applying a regeneration process that requires slightly elevated temperatures, carrier injection, and the presence of hydrogen in the silicon substrate in order to regenerate quickly and completely.

The influence of mid temperature steps up to $400{ }^{\circ} \mathrm{C}$ on the regeneration kinetics is investigated and the results can be explained with the efficacy of the regeneration process depending on the hydrogen bonding states prior to regeneration. Boron hydrogen pairs are found to be good candidates to be the relevant hydrogen source during regeneration. The long term stability of the regenerated state is tested under solar cell operating conditions, and the thermal activation energy of its destabilization is determined to be $1.25 \pm 0.05 \mathrm{eV}$.

Limiting factors for high speed regeneration processes are discussed, and a high temperature/high illumination procedure is presented, allowing complete regeneration in less than $10 \mathrm{~s}$. This makes regeneration feasible as an in line process in solar cell production.
\end{abstract}

\section{Introduction}

Silicon material containing boron as well as oxygen suffers from so called boron oxygen related degradation of minority carrier lifetime and hence of the efficiency of solar cells made from these materials [ 16 6] presumably due to latent metastable boron oxygen (BO) related defects that become recombination active under carrier injection [7 9]. Herguth et al. have shown that active $\mathrm{BO}$ related defects can be transformed into a recombination inactive state being stable under solar cell operating conditions by applying a regeneration procedure consisting of a combination of carrier injection and slightly elevated temperatures [10,11]. Recent results suggest that hydrogen might be the key factor to fast regeneration processes [12,13]: It has been shown, that if more hydrogen is introduced into the silicon bulk realized e.g. by choosing suitable hydrogenated dielectric surface coatings $[14,15]$ and optimized high temperature steps during sample processing $[16,17]$ the regeneration process becomes faster. This leads to the

\footnotetext{
* Corresponding author. Tel.: +497531882080; fax: +497531883895

E-mail addresses: Svenja.Wilking@uni-konstanz.de (S. Wilking), Cornelius.Beckh@uni-konstanz.de (C. Beckh), Sebastian.Ebert@uni-konstanz.de (S. Ebert), Axel.Herguth@uni-konstanz.de (A. Herguth), Giso.Hahn@uni-konstanz.de (G. Hahn).
}

idea that regeneration of BO related defects might in fact evolve from their passivation by hydrogen [14]. But the question arises how hydrogen can influence regeneration, even though it should mainly exist in bound states at typical regeneration temperatures of below $200{ }^{\circ} \mathrm{C}$ [18].

Mid temperature steps are known to influence hydrogen bond ing states, hence such temperature steps applied prior to regen eration are varied within this work and their influence on regeneration kinetics is monitored. The thermal stability of the resulting regenerated state is examined in the dark as well as under solar cell operating conditions. A hydrogen based regenera tion model is deduced from these measurements and acts as basis for the development of a very fast high temperature/high illumi nation regeneration process. For this purpose, regeneration kinetics is systematically investigated between $120^{\circ} \mathrm{C}$ and $400{ }^{\circ} \mathrm{C}$ at high illumination. Furthermore, limiting factors for the accel eration of the regeneration process are identified.

\section{Experimental setup}

Lifetime samples are made of $1.5 \Omega \mathrm{cm}$ boron doped Czo chralski $(\mathrm{Cz})$ grown silicon. The samples receive a $\mathrm{POCl}_{3}$ gettering step at high temperature (at $\sim 840^{\circ} \mathrm{C}$ ), the diffused layer is removed thereafter, and standard $\mathrm{SiN}_{x}: \mathrm{H}$ passivation layers 
( $\sim 75 \mathrm{~nm}$ ) are deposited on both sides using the direct plasma, low frequency plasma enhanced chemical vapor deposition (PECVD) technique of a Centrotherm system. Finally, all samples are fired at high temperature in a belt furnace. The so processed samples are completely degraded, and then regenerated under illumination at elevated temperatures. Typical minority carrier lifetime values in the samples used here are $\sim 30 \mu$ s in the degraded and $\sim 300 \mu$ s in the annealed and regenerated states. Details are given in each section separately. Finally, the stability of the regenerated state is monitored under different conditions and the stability of the surface passivation is checked by applying an annealing step at $200{ }^{\circ} \mathrm{C}$ for $10 \mathrm{~min}$.

Effective minority carrier lifetime $\tau$ is measured after each step at an injection level of $1 \cdot 10^{15} \mathrm{~cm}^{3}$ using a WCT 120 lifetime tester from Sinton Instruments. Minority carrier lifetime values are transformed into normalized defect concentration values using $N$ $(t)=1 / \tau(t) \quad 1 / \tau_{0}$ with $\tau(t)$ being the minority carrier lifetime at time $t$ and $\tau_{0}$ being the lifetime in the annealed state.

\section{Influence of mid-temperature steps on regeneration}

The hypothesis that regeneration might be a hydrogenation of BO related defects requires that hydrogen is mobile during regeneration at temperatures as low as $100^{\circ} \mathrm{C}$, which is a tem

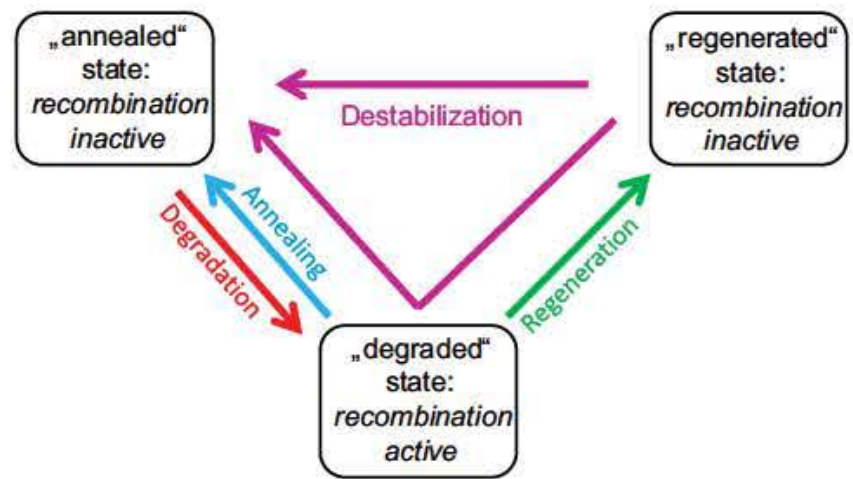

Fig. 1. Transition reactions between the three BO related defect states [25]. The transitions are activated under different temperature and illumination conditions, allowing their experimental separation. As a rule of thumb, annealing dominates at $T>100^{\circ} \mathrm{C}$ in the dark, degradation at $T<100^{\circ} \mathrm{C}$ under illumination, regeneration at $100{ }^{\circ} \mathrm{C}<T<230^{\circ} \mathrm{C}$ under illumination in well hydrogenated samples, and destabilization dominates at $T>230^{\circ} \mathrm{C}$ perature range where it is usually either trapped by impurities or by other hydrogen atoms forming molecules [18]. Hence, hydrogen has to be released under carrier injection from the atoms it is bound to. This raises the question of what kind of impurities allow a carrier enhanced detachment of hydrogen atoms at tempera tures around $100{ }^{\circ} \mathrm{C}$. When hydrogen is introduced into the silicon bulk during a high temperature step followed by a fast cool down to room temperature, subsequent tempering steps in the mid temperature range $\left(100400{ }^{\circ} \mathrm{C}\right)$ influence the hydrogen bonding states [19] which in turn might affect regeneration kinetics, especially when done at relatively low temperature.

In order to check this hypothesis, samples are pre tempered at different temperatures for $1 \mathrm{~min}$ (in air) or $15 \mathrm{~min}$ (in $\mathrm{N}_{2}$ atmo sphere) in the dark, and then degraded completely under 0.1 suns illumination at $40{ }^{\circ} \mathrm{C}$ before the regeneration procedure is applied at $130{ }^{\circ} \mathrm{C}, 0.6$ suns. The measured lifetime values are converted into effective defect concentrations (see Section 2) and are fitted using a single exponential function in order to extract the characteristic time constant as shown exemplarily in Fig. 1 (left) for samples annealed at $180{ }^{\circ} \mathrm{C}, 230{ }^{\circ} \mathrm{C}$, and $260{ }^{\circ} \mathrm{C}$, respectively. Increasing the temperature from $180^{\circ} \mathrm{C}$ to $230^{\circ} \mathrm{C}$ results in increasing regeneration rates, whereas tempering at $260{ }^{\circ} \mathrm{C}$ slows the regeneration process down again. The inverse of the time constants taken from the fits gives the regeneration rate $R_{\mathrm{R}}$ that can be used to compare the regeneration kinetics of different samples. All regeneration rates normalized to the samples annealed at $180{ }^{\circ} \mathrm{C}$ are shown in Fig. 2 (right).

Fig. 2 (right) reveals that for increasing annealing temperature the regeneration rate increases until a maximum acceleration factor of 2 to 2.5 is reached at $\sim 230^{\circ} \mathrm{C}$ for the samples pre tempered for $15 \mathrm{~min}$ and at $-290^{\circ} \mathrm{C}$ for the samples pre tempered for $1 \mathrm{~min}$. For pre tempering steps done at even higher tempera ture, the regeneration rate decreases again until no regeneration can be measured anymore in samples tempered above $400^{\circ} \mathrm{C}$ for $15 \mathrm{~min}$.

These results can be compared with data published by McQuaid et al. [19] who found that mid temperature steps result in formation of boron hydrogen (B $\mathrm{H}$ ) pairs when hydrogen had been introduced into the sample at high temperatures, followed by quenching to room temperature. They suggest that this procedure results in a non equilibrium distribution of hydrogen in the silicon sample. Hydrogen molecules at tetrahedral interstitial sites were suggested as main hydrogen configuration after cool down $[20,21]$. For high enough temperatures $\left(>170{ }^{\circ} \mathrm{C}\right.$ for $30 \mathrm{~min}$ tempering steps), hydrogen starts to redistribute with the pre ferred bound state depending on temperature. McQuaid et al.
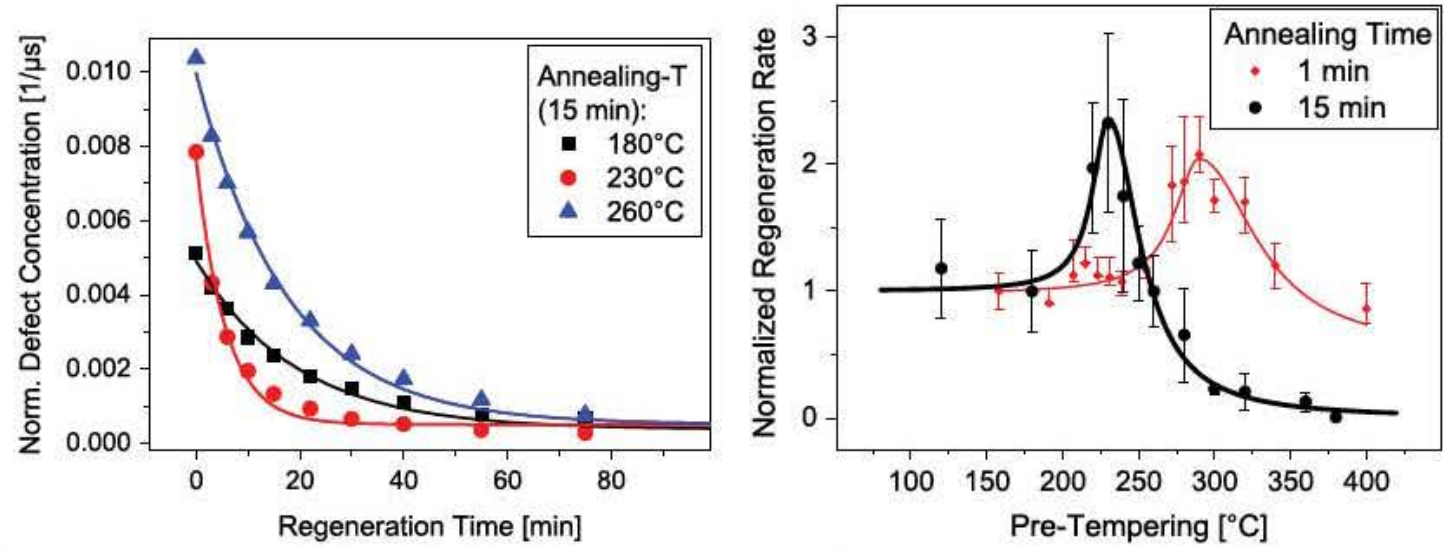

Fig. 2. (Left) Evolution of the effective defect concentration of boron-oxygen related defects during regeneration for samples annealed for 15 min at $180{ }^{\circ} \mathrm{C}, 230^{\circ} \mathrm{C}$ and $260{ }^{\circ} \mathrm{C}$, respectively. The lines are single exponential fits used to extract the regeneration rates. (Right) Normalized regeneration rates after 1 min (small red diamonds) or $15 \mathrm{~min}$ (big black dots) pre-tempering steps at different temperatures. The lines are guides to the eye. 
showed that tempering steps at $\sim 200^{\circ} \mathrm{C}$ for $30 \mathrm{~min}$ or at $\sim 175^{\circ} \mathrm{C}$ for $100 \mathrm{~min}$ lead to maximal concentration of boron hydrogen pairs whereas higher temperatures result in decreasing concen trations until virtually no boron hydrogen pairs could be found anymore after $30 \mathrm{~min}$ tempering steps above $380^{\circ} \mathrm{C}$. Jones et al. hypothesized that in the latter case hydrogen rather forms more stable hydrogen configurations, e.g. vacancy hydrogen complexes instead of binding to boron [21]. Fig. 3 shows the correlation between annealing time and the temperature where the peak is found for the B H concentration as measured by McQuaid et al. (blue dots) and for the regeneration rate (black squares). Despite the very different methods used, the data points from both processes seem to fit well on the same straight line and thus show the same thermal activation behavior. This suggests that formation of $\mathrm{B} \mathrm{H}$ pairs might also limit the regeneration of boron oxygen related defects. Hence we propose the formation of $\mathrm{B} \mathrm{H}$ pairs to cause the acceleration in regeneration that is observed after pre tempering steps around $230^{\circ} \mathrm{C}$ for $15 \mathrm{~min}$ or around $290^{\circ} \mathrm{C}$ for $1 \mathrm{~min}$. Following this argumentation, regeneration is supposed to be slightly impeded if hydrogen is bound in $\mathrm{H}_{2}$

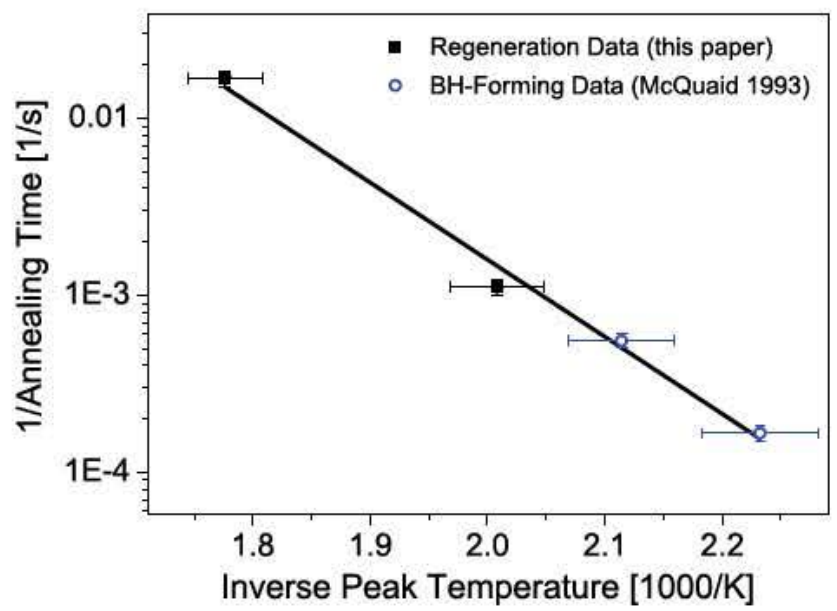

Fig. 3. Thermal activation of B-H forming (empty blue dots, data taken from McQuaid [19]) compared to the influence of pre-tempering steps on the regeneration of boron-oxygen related defects (black squares, this work). Both processes seem to be activated comparably. (For interpretation of the references to color in this figure legend, the reader is referred to the web version of this article.) molecules instead of B $\mathrm{H}$ pairs, as it is the case after cool down from high temperatures, and strongly impeded when hydrogen is bound in a more stable configuration as it would be the case after tempering steps above $380^{\circ} \mathrm{C}$ (for 30 min tempering). This seems logical assuming that the regeneration of boron oxygen related defects relies on the presence of mobile hydrogen because the more stable hydrogen configuration might not dissociate under typical regeneration conditions; hence the concentration of mobile hydrogen is low even though the overall hydrogen concentration in the silicon bulk has probably not changed significantly due to the tempering steps. Consequently, regenera tion is strongly impeded after tempering steps at around $400{ }^{\circ} \mathrm{C}$ (15 $\mathrm{min}$ ).

In contrast, B $\mathrm{H}$ pairs behave very differently: It has been shown $[22,23]$ that hydrogen detachment from boron atoms is enhanced by carrier injection possibly due to some hydrogen changing its charge state from $\mathrm{H}^{+}$to $\mathrm{H}^{0}$ after detachment. This might prevent it from instantaneously rebinding to the boron atom again, thus increasing the escape probability and reducing the dissociation energy from $1.76 \pm 0.05 \mathrm{eV}$ in the dark to $1.1 \pm 0.1 \mathrm{eV}$ under carrier injection [23]. This makes $\mathrm{B} \mathrm{H}$ pairs a probable candidate for a bonding state from which hydrogen can be released easily under typical regeneration conditions as low as $T \sim 100{ }^{\circ} \mathrm{C}$ and carrier injection. In contrast, the dissociation energy of $\mathrm{H}_{2}$ in $\mathrm{Si}$ was calculated to be around $1.6 \mathrm{eV}$ [24], making hydrogen detachment more difficult and thus a considerable amount of hydrogen being stored as $\mathrm{H}_{2}$ might slow down the regeneration of $\mathrm{BO}$ defects compared to samples containing more B H pairs. Consequently, a high concentration of B $\mathrm{H}$ pairs available in the silicon bulk before the beginning of the regenera tion process allows a high concentration of mobile hydrogen during regeneration and hence results in high regeneration rates. This can explain why $15 \mathrm{~min}$ pre tempering steps lead to increas ing regeneration rates until a maximum is reached around $230^{\circ} \mathrm{C}$ whereas higher temperatures considerably slow down the regen eration reaction.

In summary this means that it is not only the absolute hydrogen concentration in the silicon bulk that needs to be high in order to allow fast regeneration processes, but the bound hydrogen state that can be manipulated by mid temperature steps is equally important. The detrimental effect of mid temperature steps with unfavorable temperature/time combinations requires that a solar cell process should not terminate with such a temperature step when the $\mathrm{p}$ type $\mathrm{Cz}$ solar cells are supposed to regenerate quickly and reliably thereafter.
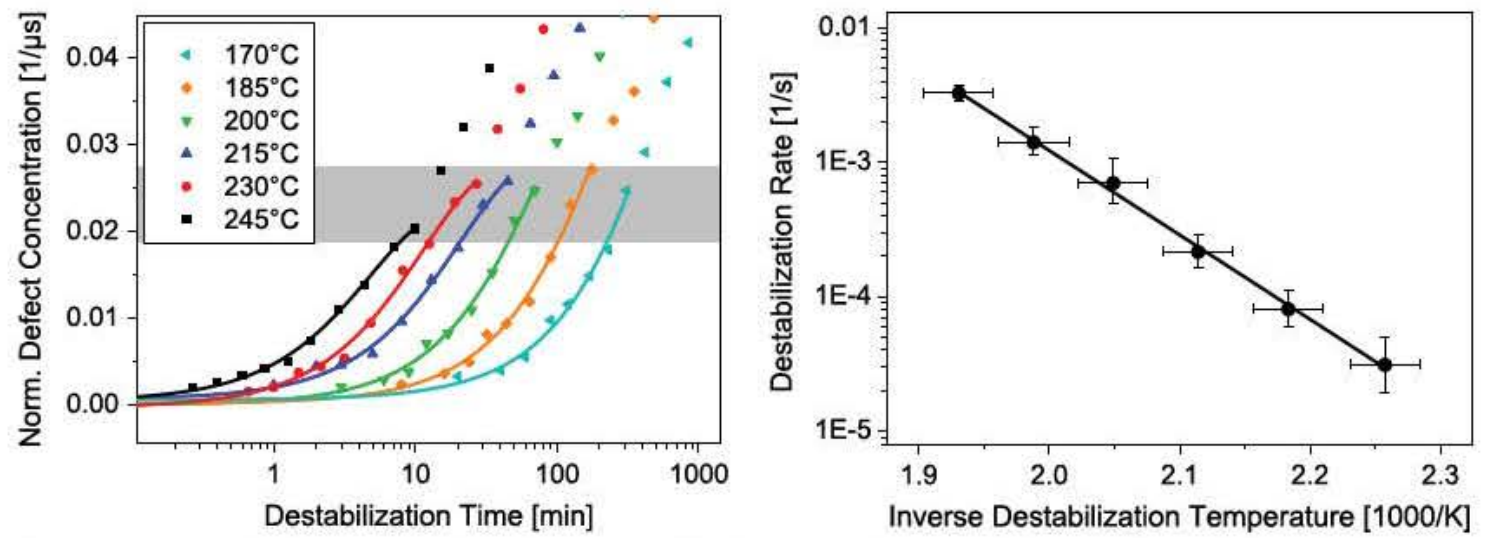

Fig. 4. (Left) Evolution of the normalized defect concentration during the destabilization process of regenerated BO related defects at different temperatures in the dark. The lines are single exponential fits to the data used to extract the destabilization rates. The gray bar represents the normalized defect concentration in the degraded state not affected by instable surface passivation. (Right) Arrhenius correlation between temperature and destabilization rate gives a thermal activation energy of 1.25 eV and a trial frequency of $5 \times 10^{9} \mathrm{~s}^{1}$. 


\section{Stability of the regenerated state}

\subsection{Thermal stability}

When the regeneration process is used in order to neutralize harmful BO related defects in boron doped and oxygen rich silicon solar cells, the stability of the regenerated BO defect state is a crucial question. Herguth et al. [25] have monitored changes in the open circuit voltage of solar cells with regenerated BO defects and showed that the destabilization of regenerated BO defects is thermally activated with an activation energy of $0.98 \pm 0.01 \mathrm{eV}$ and a characteristic frequency of $(1.5 \pm 0.5) \cdot 10^{7} \mathrm{~s}{ }^{1}$ [25]. In this work, we present measurements on a larger temperature range using lifetime samples that allow a direct access to the evolution of the $\mathrm{BO}$ related defect concentration. All lifetime samples presented in this section are fully regenerated at $130^{\circ} \mathrm{C}, 1.2$ suns before being treated at the respective temperatures in the dark. After every tempering step, the samples are fully degraded at $45^{\circ} \mathrm{C}$, 0.1 suns for $24 \mathrm{~h}$. Then the minority carrier lifetime is measured and used for the calculation of the changes in the normalized defect concentration $N(t)=1 / \tau(t) \quad 1 / \tau_{\text {Reg }}$ with $\tau(t)$ being the minority carrier lifetime at time $t$ and $\tau_{\text {Reg }}$ being the lifetime in the regenerated state. The evolution of the defect concentration with destabilization time is given in Fig. 4 (left), the corresponding Arrhenius plot used to extract the thermal activation energy of the destabilization reaction and the characteristic frequency is shown in Fig. 4 (right).

The thermal activation energy of the destabilization reaction is calculated to $1.25 \pm 0.05 \mathrm{eV}$ with a characteristic frequency of $(5 \pm 4) 10^{9} s^{1}$. For longer destabilization times the fits become unreliable due to degradation of the surface passivation, hence the last data points of each sample are not used for fitting the single exponential functions used to calculate the characteristic time constants. The normalized defect concentration in the degraded BO state lying between $0.018 \mu \mathrm{s}^{1}$ and $0.027 \mu \mathrm{s}^{1}$ was chosen as upper limit. As a consequence, the values for activation energy and characteristic frequency given here are to be considered as minimum, respectively maximum, values because the increase in defect concentration might be slightly accelerated due to degrada tion effects that are not caused by the destabilization of BO related defects, e.g., degradation of the $\mathrm{SiN}_{\mathrm{x}}: \mathrm{H}$ surface passivation layer. In fact, at least $20 \%$ of the defect concentration measured after the whole destabilization process is due to defects that cannot be rendered inactive by a typical BO annealing treatment of $10 \mathrm{~min}$ at $200{ }^{\circ} \mathrm{C}$ in the dark. Extrapolating the Arrhenius correlation to lower temperatures gives destabilization time constants of $\geq 8800$ $\left(\begin{array}{c}+25300 \\ 2500\end{array}\right)$ years at $25^{\circ} \mathrm{C}$ and $\geq 53\left(\begin{array}{c}+110 \\ 7\end{array}\right)$ years at $60{ }^{\circ} \mathrm{C}$. Hence, destabilization of $\mathrm{BO}$ related defects in the dark is not going to pose a major problem during the lifespan of a typical solar cell, as already predicted by Herguth et al. [25], especially as the solar cell only reaches higher temperatures around $60^{\circ} \mathrm{C}$ by illumina tion which in turn most probably promote a slow regeneration neutralizing the destabilization effect.

\subsection{Stability under solar cell operating conditions}

The 3 state model by Herguth et al. [25] of the transition reactions between the different BO states assumes that the regenerated state of the $\mathrm{BO}$ related defect becomes instable at higher temperatures (see Section 4.1 for the relevant values). Destabilization of the regenerated state in the dark leads directly or indirectly into the instable annealed state again. Under carrier injection, boron oxygen related defects then transform to the degraded state. If this happens, an overall decrease of minority carrier lifetime is observed that is caused by the destabilization of the regenerated state. But for slightly higher temperatures com bined with carrier injection, a certain fraction of the boron oxygen defects will regenerate again. Hence, the injection level defines to what extent destabilization and regeneration compete and conse quently what the equilibrium defect concentration in the regen erated state is. Higher injection favors the regeneration reaction relative to the destabilization process and hence a long term BO related defect concentration lying between the one of the com pletely degraded and the one of the completely regenerated state is to be expected. This equilibrium defect concentration defines the long term stability of the regenerated state under illumination.

In order to investigate the long term stability of regenerated BO related defects, lifetime samples that have been regenerated completely at $130^{\circ} \mathrm{C}, 1.2$ suns undergo a treatment at $60^{\circ} \mathrm{C}$ sample temperature under 1 sun illumination imitating solar cell operat ing conditions in the field. This treatment leads to a long term defect concentration of less than $10 \%$ of the BO related defect concentration in the degraded BO state (see Fig. 5, left). However, a subsequent annealing step (blue triangle) deactivating any BO defect was applied to check which part of the observed degrada tion is actually due to BO related defects. As the observed difference (black to blue) only corresponds to $1 / 3$ of the observed degradation, approximately $2 / 3$ of the defects developed after 60
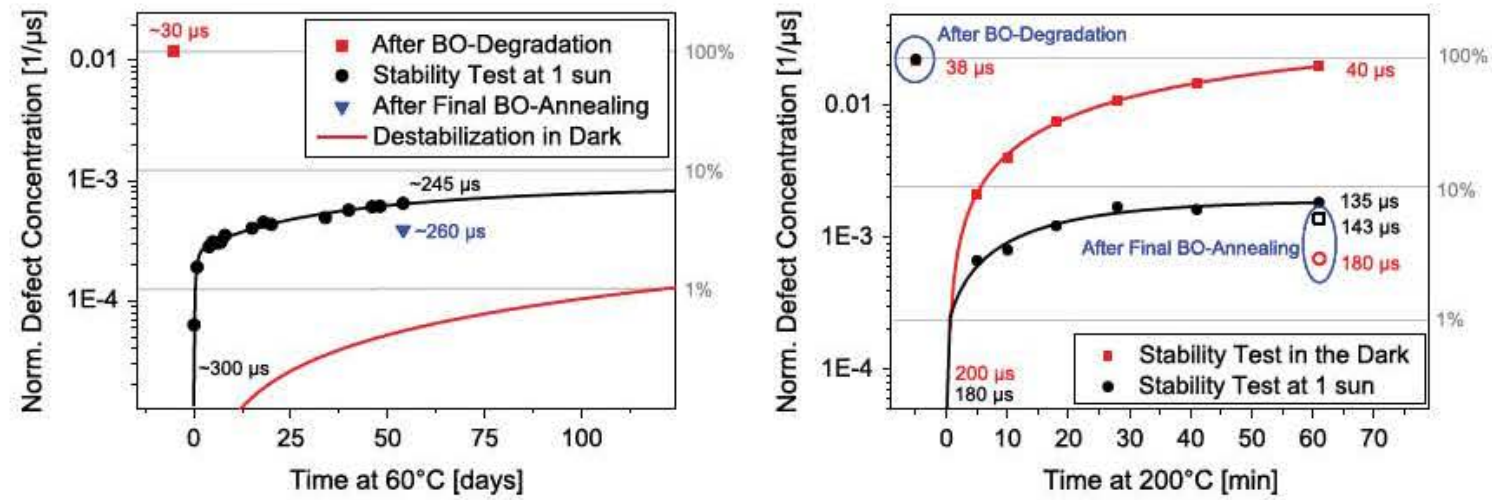

Fig. 5. (Left) Evolution of normalized defect concentration under 1 sun, $60^{\circ} \mathrm{C}$ starting from the regenerated state at zero defect concentration. An accelerated initial destabilization followed by saturation at low defect density level is found under illumination (black data points) compared to the same procedure in the dark (red line, calculation from higher temperature measurements). Minority carrier lifetime values measured after degradation, regeneration, 60 days of tempering, and final BO annealing are given. (Right) Evolution of normalized defect concentration caused by tempering of regenerated samples at $200^{\circ} \mathrm{C}$ in the dark and under 1 sun illumination, respectively. The open symbols correspond to the values measured after final $\mathrm{BO}$ annealing. (For interpretation of the references to color in this figure legend, the reader is referred to the web version of this article.) 
days are not correlated to BO related defects, but to other defects that have become recombination active under these conditions, e.g. a degradation of the surface passivation. Thus, the real BO destabilization process would be slightly slower and would result in a considerably lower long term defect concentration.

A closer look into the evolution of the defect concentration with time (Fig. 5, left) reveals two main differences between destabilization in the dark (red line, calculated from the values determined in Section 4.1) and changes in defect concentration under illumination (black dots): First, all BO defects will be reactivated by long enough tempering steps in the dark, whereas a low intermediate defect concentration of less than $3 \pm 2 \%$ is reached under illumination. This is in agreement with the three state BO model [25]. Second, the increase in defect concentration under illumination consists of two steps, of which the fast one dominates at the beginning. This is contrarily to the destabilization in the dark where the evolution of the defect density can be fitted using a single exponential function.

We can state that although regenerated BO related defects becoming instable might be one of the reasons for the increase in defect concentration under illumination, the dynamic long term equilibrium for $97 \pm 2 \%$ of all BO related defects is in the regen erated state that is characterized by high minority carrier lifetime values and hence high solar cell efficiency. As a consequence, the partly destabilization of the regenerated BO defect state under solar cell operating conditions is virtually irrelevant on solar cell level.

At higher temperature $\left(200^{\circ} \mathrm{C}\right.$, Fig. 5 , right), where destabiliza tion proceeds much faster, the influence of illumination particu larly on the saturation of defect concentration as well as on the effect of the final BO annealing step becomes even clearer, even though fast initial changes in defect concentration cannot be resolved here. After every tempering step, the samples are stability checked for $24 \mathrm{~h}$ at $45^{\circ} \mathrm{C}, 0.1$ suns in order to make sure that annealing of BO defects has no influence on the measured lifetime. Tempering in the dark results in complete destabilization of the regenerated BO defects and final BO annealing is able to consider ably reduce defect concentration meaning that $97 \pm 2 \%$ of all "new" defects are actually BO defects. The final BO annealing not being able to reset defect concentration to zero means that additionally, not $\mathrm{BO}$ related defects come into existence during the tempering steps. Tempering at 1 sun illumination draws a completely different picture: hardly any defect $(2 \pm 2 \%)$ can be neutralized by the final $\mathrm{BO}$ annealing step, hence virtually no BO defect got destabilized by this $200^{\circ} \mathrm{C} / 1$ sun treatment. Again, we ascribe this to renewed regeneration proceeding faster than the destabilization process under these conditions and thus leading to no net destabilization.

\section{High-speed regeneration}

The concentration of recombination active $\mathrm{BO}$ related defects and hence the minority charge carrier lifetime is determined by the rates of the four major BO state transitions (see [25] for details): annealing (deactivating BO related defects; the resulting "annealed" state is instable under carrier injection), degradation (activating BO related defects), regeneration (deactivating BO related defects; the resulting "regenerated" state is stable under carrier injection) and destabilization (reactivating inactive, "regen erated" BO related defects) (see also Fig. 1). Whereas rates for annealing, degradation and probably destabilization only depend on temperature under typical regeneration conditions, regenera tion can be accelerated by increasing illumination intensity. In addition, the regeneration rate can be increased by improved hydrogenation of the silicon bulk [14] and according to Section 3 the ratio of hydrogen being in a favorable bonding state. Altogether, temperature, injection level, and hydrogen will deter mine which transition reactions dominate, and thus what is the occupation probability of the different BO states in long term equilibrium.

In order to allow regeneration dominated processes, well hydrogenated and suitably annealed $\left(200{ }^{\circ} \mathrm{C}, 10 \mathrm{~min}\right)$ lifetime samples are regenerated at a high illumination intensity of 2.7 suns. Regeneration temperature is varied between $120^{\circ} \mathrm{C}$ and $400^{\circ} \mathrm{C}$. This reveals the transition between the lower temperature range where regeneration dominates, and the higher temperature range where destabilization dominates. In the mid temperature range around $200{ }^{\circ} \mathrm{C}$, regeneration and annealing have similar transition rates and hence compete directly. Since both processes result in high lifetimes, they can only be separated after a subsequent degradation step that is performed at $45^{\circ} \mathrm{C}$ for $24 \mathrm{~h}$ after every "regeneration" step. After that time a stable lifetime is reached and all BO related defects that might have been trans formed to the annealed state instead of the regenerated one have been degraded, so that an increase in lifetime compared to the previous step can clearly be identified as regeneration of BO related defects. Thus, all data shown in this section is free from possible influence of the annealing reaction.

Characteristic time constants and corresponding regeneration rates for different regeneration temperatures are given in Figs. 6 and 7. Fig. 6 shows the regeneration process in the low
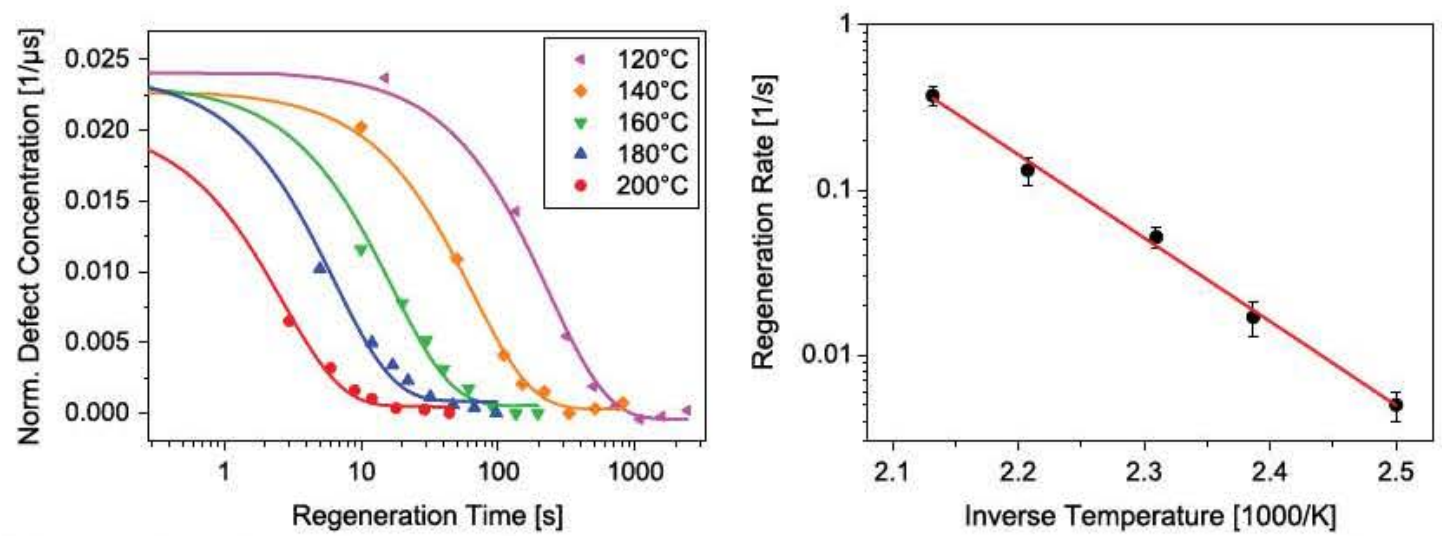

Fig. 6. (Left) Evolution of normalized $\mathrm{BO}$ related defect concentration with time for regeneration processes at 2.7 suns and temperatures from $120{ }^{\circ} \mathrm{C}$ to $200{ }^{\circ} \mathrm{C}$. The lines are single exponential fits to the data used to extract the regeneration time constants and the regeneration rates. (Right) Arrhenius plot of regeneration processes measured between $120^{\circ} \mathrm{C}$ and $200^{\circ} \mathrm{C}$ at 2.7 suns illumination. 

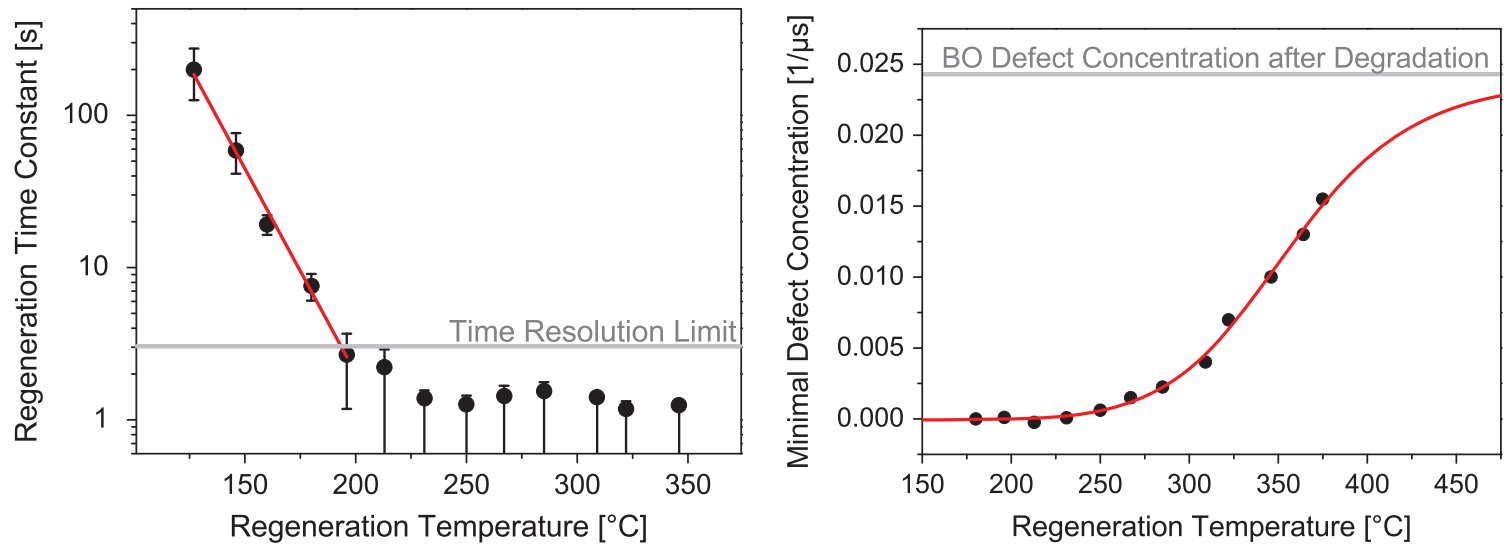

Fig. 7. (Left) Characteristic time constants of regeneration processes measured at different temperatures and 2.7 suns illumination. Lifetimes are stable after all regeneration processes. Regeneration time constants below $3 \mathrm{~s}$ could not be quantified reliably due to the limited time resolution of the measurement setup. (Right) Minimal normalized BO defect concentration that can be reached during regeneration at 2.7 suns illumination. The red line is a guide to the eye. The gray line represents the defect concentration in the degraded state. (For interpretation of the references to color in this figure legend, the reader is referred to the web version of this article.)

temperature range below $200{ }^{\circ} \mathrm{C}$ where the regeneration time constants decrease steadily with temperature (see also Fig. 7, left) corresponding to an Arrhenius correlation between temperature and regeneration rate (Fig. 6, right). Hence, the regeneration process is thermally activated with an activation energy of $0.98 \pm 0.06 \mathrm{eV}$ and a characteristic frequency of $(1.25 \pm 0.08)$ $10^{10} \mathrm{~s}^{1}$. The relatively high regeneration rates already at low temperature have the important advantage that a consider able increase in regeneration temperature is possible without compromising the regeneration process, because the regenera tion rates are high compared to annealing, degradation and destabilization rates.

Regeneration time constants decrease with increasing tem perature until the measurement setup starts limiting time resolu tion above $\sim 200^{\circ} \mathrm{C}$. Fig. 7 (right) shows the minimal BO related defect concentration that can be reached during the regeneration process at the respective temperature at 2.7 suns. In the tempera ture range above $230{ }^{\circ} \mathrm{C}$ the destabilization process becomes more and more important, causing reactivation of BO related defects resulting in incomplete regeneration as predicted by Herguth et al. [25].

As a result, regeneration temperature is a tradeoff between accelerated regeneration and decreasing completeness at high temperature and has to be chosen carefully depending on the injection level: at 2.7 suns, complete regeneration can be achieved at temperatures between $200{ }^{\circ} \mathrm{C}$ and $230{ }^{\circ} \mathrm{C}$ with a time constant of $<3 \mathrm{~s}$ meaning that complete regeneration can be realized in less than $10 \mathrm{~s}$. This process makes the regeneration of $\mathrm{BO}$ related defects suitable for in line solar cell production. With a successful implementation of this high speed regeneration step one could overcome any efficiency limitation due to BO related defects in boron doped oxygen rich silicon material. The regeneration pro cedure is patent pending.

\section{Hydrogen related regeneration model}

Many different experiments [12 17] led to the idea of hydrogen playing an important role in the regeneration of BO related defects, but it is yet unclear how hydrogen can influence this reaction. At temperatures as low as $100^{\circ} \mathrm{C}$, hydrogen is typically bound to impurities or to other hydrogen atoms forming mole cules [18]. The results from Section 3 suggest that hydrogen atoms might be bound in a configuration of which the dissociation is considerably enhanced under carrier injection, e.g. B $\mathrm{H}$ pairs.
Splitting of B $\mathrm{H}$ pairs has an activation energy of $1.1+0.1 \mathrm{eV}$ under carrier injection [23]. This fits well with the activation energy of the regeneration process that was determined to be $0.98 \pm 0.06 \mathrm{eV}$ (Section 5). In the case where a silicon wafer is cooled down fast enough after a high temperature hydrogenation step, so that a considerable amount of hydrogen is bound to boron atoms, splitting of these pairs might limit the regeneration of $\mathrm{BO}$ related defects. Different thermal conditions either leading to hydrogen being mainly bound as $\mathrm{H}_{2}$ or as other more stable hydrogen complexes (e.g. vacancy hydrogen complexes) might lead to other reactions limiting the regeneration of BO defects resulting in differing activation energy values. For example, very low cooling rates after high temperature steps might drive a considerable amount of hydrogen into a stable hydrogen bonding state similar to the one that can be achieved by tempering steps around $400{ }^{\circ} \mathrm{C}$. Hence, the temperature dependent distribution of hydrogen atoms into different bound hydrogen states might directly influence regeneration kinetics.

At typical regeneration temperatures, the main hydrogen species in $\mathrm{p}$ type silicon is the positively charged $\mathrm{H}^{+}$whose diffusivity is relatively low due to Coulomb interaction with the lattice atoms [26], and in addition to that, $\mathrm{H}^{+}$diffusion has been found to be severely impeded in oxygen rich $\mathrm{Cz}$ silicon (activation energy of $1.23 \mathrm{eV}$ ) [27]. Thus, diffusion of $\mathrm{H}^{+}$cannot be of major importance for the regeneration reaction. In contrary, uncharged $\mathrm{H}^{0}$ that comes into existence under carrier injection due to a change in Fermi level behaves very different and has a diffusivity 5 orders of magnitude higher than $\mathrm{H}^{+}$[28]. We therefore propose a threefold influence of illumination on the regeneration process: First, carrier injection can considerably lower the escape barrier of hydrogen atoms from impurities they were bound to, e.g., boron. Second, carrier injection renders neutral a considerable amount of hydrogen allowing unhin dered diffusion as $\mathrm{H}^{0}$. Third, the $\mathrm{BO}$ related defect being positively charged in p type silicon [29], a hydrogen passivation with $\mathrm{H}^{+}$is very improbable whereas $\mathrm{H}^{0}$ might bind easily to the complex, especially when considering the possibility that the $\mathrm{BO}$ related defect might change its charge state under carrier injection, too. In consequence, we assume that the regeneration of $\mathrm{BO}$ related defects is a hydrogen passivation by $\mathrm{H}^{0}$ atoms. This model gives a possible explanation to why a combination of high hydrogen content in the silicon bulk, slightly elevated temperatures, and carrier injection is needed for the regeneration of $\mathrm{BO}$ related defects to occur.

In this picture, the thermal activation energy of the destabiliza tion reaction could either correspond to dissolution of the $\mathrm{BO}$ related defect or to hydrogen detachment from the defect. In the 
latter case, the activation energy of $1.23 \pm 0.04 \mathrm{eV}$ (Section 4.1) would correspond to the dissociation energy of the hydrogenated BO related defect.

\section{Conclusions}

Investigating the effect of mid temperature steps on the regeneration kinetics has shown that regeneration can be accel erated by temperature steps that are supposed to result in hydrogen bonding to boron atoms, whereas temperature steps that might result in more stable hydrogen configurations con siderably slow down regeneration. A possible explanation is that $\mathrm{B} \mathrm{H}$ pairs can dissociate during regeneration, whereas this is not the case for hydrogen bound in other configurations. Hence, regeneration is strongly impeded for the latter case.

The stability of the regenerated state was investigated in the dark as well as under illumination. Whereas destabilization in the dark takes several hundred years at room temperature and hence is without importance for solar cells, illumination was found to result not only in destabilization but also in renewed regeneration. As a consequence, an intermediate long term defect density level is reached that corresponds to less than $3 \%$ of all BO related defects being in a recombination active state. Hence, destabilization of the regenerated BO related defect is virtually irrelevant under solar cell operating conditions.

A combination of all findings was used to determine what effects limit regeneration processes executed at different tempera tures. In the temperature range below $200{ }^{\circ} \mathrm{C}$ regeneration was found to be thermally activated with an activation energy of $0.98 \pm 0.06 \mathrm{eV}$ and a trial frequency of $(1.25 \pm 0.08) 10^{10} \mathrm{~s}{ }^{1}$. For temperatures above $230{ }^{\circ} \mathrm{C}$ destabilization becomes more and more important, resulting in incomplete regeneration. Hence, the temperature slot between $200{ }^{\circ} \mathrm{C}$ and $230{ }^{\circ} \mathrm{C}$ was found to be suitable for realizing a high temperature/high injection regenera tion process that allows suitably hydrogenated silicon wafers to regenerate completely in less than $10 \mathrm{~s}$, making regeneration a feasible in line process for solar cell production. Consequently, the efficiency of solar cells made from boron doped oxygen rich silicon material is not limited by boron oxygen related defects anymore.

\section{Acknowledgments}

The authors would like to thank L. Mahlstaedt and T. Wiedenmann for technical support during sample preparation. Part of this work was supported by the German Federal Ministry for the Environment, Nature Conservation and Nuclear Safety.

\section{References}

[1] H. Fischer, W. Pschunder, Investigation of photon and thermal induced changes in siliconsolar cells, in: Proceedings of the 10th IEEE PVSC, Palo Alto, USA, 1973 p. 404
[2] J. Knobloch, S.W. Glunz, D. Biro, W. Warta, E. Schaffer, W. Wettling, Solar cells with efficiencies above $21 \%$ processed from Czochralski grown silicon, in: Proceedings of the 25th IEEE PVSC, New York, USA, 1996, p. 405.

[3] J. Schmidt, A.G. Aberle, Accurate method for the determination of bulk minority-carrier lifetimes of mono-and multicrystalline silicon wafers, J. Appl. Phys. 81 (1997) 6186.

[4] S. Dubois, N. Enjalbert, J.P. Garandet, Slow down of the light-induceddegradation in compensated solar-grade multicrystalline silicon, Appl. Phys. Lett. 93 (10) (2008) 103510.

[5] M. Forster, E. Fourmond, F.E. Rougieux, A. Cuevas, R. Gotoh, K. Fujiwara, M. Lemiti, Boron-oxygen defect in Czochralski-silicon co-doped with gallium and boron, Appl. Phys. Lett. 100 (4) (2012) 042110.

[6] D. Macdonald, A. Liu, A. Cuevas, B. Lim, J. Schmidt, The impact of dopant compensation on the boron-oxygen defect in p-and n-type crystalline silicon, Phys. Status Solidi A 208 (3) (2011) 559.

[7] S.W. Glunz, S. Rein, W. Warta, J. Knobloch, W. Wettling, Degradation of carrier lifetime in Cz silicon solar cells, Sol. Energy Mater. Sol. Cells 65 (2001) 219.

[8] K. Bothe, J. Schmidt, Electronically activated boron-oxygen-related recombination centers in crystalline silicon, J. Appl. Phys. 99 (2006) 013701.

[9] V.V. Voronkov, R. Falster, Latent complexes of interstitial boron and oxygen dimers as a reason for degradation of silicon-based solar cells, J. Appl. Phys. 107 (2010) 053509.

[10] A. Herguth, G. Schubert, M. Kaes, G. Hahn, in: Proceedings of the 32nd IEEE PVSC (4th WCPEC), Waikoloa, USA, 2006, p. 940.

[11] A. Herguth, G. Schubert, M. Kaes, G. Hahn, Investigations on the long time behavior of the metastable boron-oxygen complex in crystalline silicon, Prog. Photovol. Res. Appl. 16 (2007) 135.

[12] K.A. Münzer, Hydrogenated silicon nitride for regeneration of light induced degradation, in: Proceedings of the 24th EU-PVSEC, Hamburg, Germany, 2009 p. 1558.

[13] G. Krugel, W. Wolke, J. Geilker, S. Rein, R. Preu, Impact of hydrogen concentration on the regeneration of light induced degradation, Energy Proc. 8 (2011) 47.

[14] S. Wilking, A. Herguth, G. Hahn, Influence of hydrogen on the regeneration of boron-oxygen related defects in crystalline silicon, J. Appl. Phys. 113 (2013) 194503.

[15] S. Wilking, A. Herguth, G. Hahn, Influence of hydrogenated passivation layers on the regeneration of boron-oxygen related defects, Energy Proc. 38 (2013) 642.

[16] S. Wilking, S. Ebert, A. Herguth, G. Hahn, Influence of short high temperature steps on the regeneration of boron-oxygen related defects, in: Proceedings of the 28th EUPVSEC, Paris, France, 2013, p. 34.

17] S. Wilking, S. Ebert, A. Herguth, G. Hahn, Influence of hydrogen effusion from hydrogenated silicon nitride layers on the regeneration of boron-oxygen related defects in crystalline silicon, J. Appl. Phys. 114 (2013) 194512.

[18] S.J. Pearton, et al., Hydrogen in crystalline semiconductors, Appl. Phys. A 43 (1987) 153

[19] S.A. McQuaid, et al., Solubility of hydrogen in silicon at $1300{ }^{\circ} \mathrm{C}$, Appl. Phys. Lett. 62 (14) (1993) 1612.

[20] A.W.R. Leitch, V. Alex, J. Weber, Raman spectroscopy of hydrogen molecules in crystalline silicon, Phys. Rev. Lett. 81 (2) (2000) 421.

[21] R. Jones, B.J. Coomer, J.P. Goss, B. Hourahine, A. Resende, The interaction of hydrogen with deep level defects in silicon, Solid State Phenom. 71 (2000) 173.

[22] C.H. Saeger, et al., Two-step debonding of hydrogen from boron acceptors in silicon, Appl. Phys. Lett. 59 (5) (1991) 585

[23] T. Zundel, J. Weber, Boron reactivation kinetics in hydrogenated silicon after annealing in the dark or under illumination, Phys. Rev. B 43 (5) (1991) 4361.

[24] C.G. Van de Walle, Energies of various configurations of hydrogen in silicon, Phys. Rev. B 49 (1994) 4579.

[25] A. Herguth, G. Hahn, Kinetics of the boron-oxygen related defect in theory and experiment, J. Appl. Phys. 108 (2010) 114509.

[26] C. Herring, N.M. Johnson, C.G. Van de Walle, Energy levels of isolated interstitial hydrogen in silicon, Phys. Rev. B 64 (2001) 125209.

27] Y.L. Huang, Y. Ma, R. Job, A.G. Ulyashin, Hydrogen diffusion at moderate temperatures in p -type Czochralski silicon, J. Appl. Phys. 96 (2004) 7080.

[28] D. Mathiot, Modelling of hydrogen diffusion in n- and p-type silicon, Phys. Rev. B 40 (8) (1989) 5867.

29] K. Bothe and J. Schmidt, Fast-forming boron-oxygen-related recombination center in crystalline silicon, Appl. Phys. Lett. 87 (2005) 262108. 